\title{
Nationwide Survey and Identification of Potential Stress Factor in Sensitive Skin of Chinese Women
}

This article was published in the following Dove Press journal:

Clinical, Cosmetic and Investigational Dermatology

\author{
Xiaoqing Xiao ${ }^{1, *}$ \\ Liyuan Qiao $\mathbb{D}^{2, *}$ \\ Rui $\mathrm{Ye}^{2}$ \\ Fuguo Zuo'
}

'Department of Dermatology, Shanghai East Hospital, Tongji University School of Medicine, Shanghai, People's Republic of China; ${ }^{2}$ Department of Science, Inertia Shanghai Biotechnology Co., Ltd., Shanghai, People's Republic of China

*These authors contributed equally to this work
Correspondence: Rui Ye

Department of Science, Inertia Shanghai

Biotechnology Co., Ltd., No. 45 East

Huaihai Road, Huangpu District, Shanghai,

People's Republic of China

Tel +86-I868I4860I4

Email18128225I@qq.com

Fuguo Zuo

Department of Dermatology, Shanghai East Hospital, Tongji University School of

Medicine, No. 150, Jimo Road, Pudong

District, Shanghai, People's Republic of China

$\mathrm{Tel} / \mathrm{Fax}+86-021-38804518$

Email 873106322@qq.com

\begin{abstract}
Purpose: Sensitive skin is characterized by uncomfortable sensations in response to a number of factors. We performed a large-scale study to investigate the prevalence of sensitive skin at all ages and the impacts of related factors across China.

Methods: A nationwide sampling of the Chinese population aged over 18 was conducted. Subjects were categorized into sensitive and non-sensitive groups, and critical differences between these two groups were investigated.

Results: In total, 22,085 questionnaires were collected from Chinese women with sensitive skin. The prevalence of sensitive skin is $49.6 \%$ and is associated with age, skin type, geographic area of subjects, and other factors. Heavy life stress and the application of several cosmetic products also affect the prevalence of sensitive skin.

Conclusion: Having a combination or oily skin type, living in the municipalities, being under heavy stress, and applying several cosmetic products will increase skin stress and contribute to the occurrence of sensitive skin.
\end{abstract}

Keywords: Chinese women, cosmetic product usage, large-scale study, sensitive skin, skin stress

\section{Introduction}

Sensitive skin is characterized by uncomfortable sensations, such as prickling, burning, tingling, pain, or itchiness, and occasionally erythema or acne, in response to a number of physical or chemical factors, such as ultraviolet radiation, climate, or environment. $^{1,2}$

The mechanism of sensitive skin has not been elucidated, but it is now believed that it is neither an allergy nor an immune response. ${ }^{3}$ There are several possible mechanisms. One is skin barrier impairment, which leads to an increase in epidermal water loss and a reduction in resilience to external stimuli or irritants. ${ }^{4}$ Studies have found that the cutaneous nervous system also plays a role in skin sensitivity. ${ }^{5}$ Vasoactive intestinal polypeptide, substance $\mathrm{P}$, calcitonin gene-related polypeptide, and other neurotransmitters appear to be inducers of neurogenic inflammation, inducing vasodilation and mast cell degranulation. ${ }^{6,7}$ Non-specific inflammation may also be related to the release of interleukin 1, interleukin 8, prostaglandin E2, prostaglandin F2, and tumor necrosis factor alpha. ${ }^{6}$ Genetic factors have also been found to affect skin sensitivity. Transient receptor potential vanilloid 1 (TRPV1) is a non-selective cation channel protein that is related to neurogenic inflammation and pruritus. ${ }^{8,9}$ According to the research of Sun et al, ${ }^{10}$ two specific TRPV1 genotypes are related to skin sensitivity, indicating that TRPV1 might contribute to the pathogenesis of sensitive skin. 
The term "sensitive skin" has become more familiar to the public in recent years. It is often perceived as a frequent disorder, while it has an unexpected impact on patients' quality of life. ${ }^{11}$ Studies on skin sensitivity have been conducted in many countries and for different regions, such as the United States, France, Japan, Europe, etc. ${ }^{12-15}$ Research on sensitive skin in China has mainly been undertaken in big cities, such as Beijing, Shanghai, or Guangzhou, with sample sizes of only a few hundred participants; this is under representative of China's population of 1.4 billion. ${ }^{16}$ In addition, many factors may have impacts on skin sensitivity, such as the increasing usage of cosmetics and heavy life stress. We performed a large-scale study to investigate the prevalence of skin sensitivities at all ages and the impacts of related factors across China.

\section{Methods}

\section{Participants and Questionnaire}

The participants were taken from the customer base of Inertia Shanghai Biotechnology Co., Ltd. The survey was conducted by having participants fill in a questionnaire online. In total, 23,113 questionnaires were collected.

There are two parts to the questionnaire. The first part of the questionnaire is about demographics (geographical area, age, sex) and skin type. The second collects information about skin sensitivity and lifestyle. Subjects were requested to rate their skin as "very sensitive," "slightly sensitive," "not sensitive at all," or "not sure." They also responded to an open question regarding their perception of the onset of skin redness, itchiness, or dryness in the presence of different factors, such as usage of cosmetics, make-up conditions, usage of make-up removers, transportation, and life stress. We captured the 2019 annual average air quality index of all provinces and cities in China as given by the Ministry of Ecology and Environment of China to evaluate the relationship between air quality index and skin sensitivity prevalence. ${ }^{17}$

To characterize sensitive skin among subjects, the characteristics of subjects who responded to the sensitivity question as having either "slightly sensitive" or "very sensitive" skin (sensitive skin group) were compared with those of the subjects who rated their skin as "not sensitive at all" (non-sensitive skin group). ${ }^{12,13}$ Subjects who rated their skin as "not sure" were excluded from further analysis.

\section{Ethical Considerations}

The study protocol was approved by the Ethical Committee of the Department of Dermatology [Approved ID: 2020-050], Shanghai East Hospital. Participants provided informed consent, and the study was conducted in accordance with the Declaration of Helsinki. Personal identifiers were removed from the dataset before analyses were undertaken.

\section{Statistical Analysis}

Quantitative variables were compared between groups with Student's $t$-test or analysis of variance (ANOVA). Where the conditions for the applications of these tests were not met, the Wilcoxon and Kruskal-Wallis non-parametric tests were performed. Categorical variables were compared using an appropriate test or using Fisher's exact test if the conditions were not completely met.

To evaluate the relationships between age, skin type, geographical area, specific skin symptoms, make-up condition, use of cosmetics, use of make-up removers, life stress, air conditioning, and the presence of skin sensitivity, a general logistic model was used in the study. Odds ratios with $95 \%$ confidence intervals were calculated after adjustment for potential confounders. Estimates for each category within the reference group were derived from the same logistic regression model after adjustment for confounders.

Statistical analyses were performed using the computing environment $\mathrm{R}$ version 3.6.2 (R Development Core Team, 2005). Statistical significance was considered for $P<0.05$.

\section{Results}

\section{Sample Population}

A total of 23,526 eligible participants were enrolled and 23,113 questionnaires were completed. Of the respondents who completed the questionnaires, there were 22,556 women and 557 men, aged from 18 to 80 , with an average age of $48.4 \pm 13.9$ years. The characteristics of the subjects are shown in Table 1. Men and subjects who rated their skin as "not sure" were excluded from further analysis. In total, 22,085 questionnaires on the subject of skin sensitivity completed by Chinese women were analyzed.

\section{Prevalence of Skin Sensitivity in Different Age Groups}

The prevalence of sensitivity is significant in different age groups $(P<0.001)$ (Table 2$)$. Subjects who were younger 
Table I Sample Population

\begin{tabular}{|l|l|l|}
\hline Characteristics & N & $\%$ \\
\hline Gender & 22,556 & $97.6 \%$ \\
\hline Female & 557 & $2.4 \%$ \\
Male & \multicolumn{2}{|l|}{} \\
\hline Age & 292 & $1.3 \%$ \\
\hline I8-20 & 2922 & $12.9 \%$ \\
$2 I-30$ & 3310 & $14.6 \%$ \\
$3 I-40$ & $54 I 2$ & $23.9 \%$ \\
$4 I-50$ & 5728 & $25.3 \%$ \\
$5 I-60$ & 4009 & $17.7 \%$ \\
$6 I-70$ & 947 & $4.2 \%$ \\
$7 I-80$ & \multicolumn{2}{|l}{} \\
\hline Sensitivity self-declared & $1 \mathrm{I}, 475$ & $49.6 \%$ \\
\hline Not sensitive at all & 9537 & $41.3 \%$ \\
Slightly sensitive & 1608 & $7.0 \%$ \\
Very sensitive & 493 & $2.1 \%$ \\
Not sure & 23,113 & \\
\hline Total & & \\
\hline
\end{tabular}

(20-30 years old) were more likely to claim to have sensitive or very sensitive skin than older participants ( $>30$ years old), with rates of $65.8 \%$ in the 20 s group and of $57.2 \%$ in the $30 \mathrm{~s}$ group; in older women, the rate drops, to less than $50 \%$ in women $51-60$ years old and to $39.3 \%$ in women $61-70$ years old.

\section{Sensitivity and Skin Symptoms}

Participants stated that they had different symptoms relative to skin sensitivity. Of those questioned, 2094 (19.1\%) had skin redness, 724 (6.6\%) reported itchiness, and 2898 (26.4\%) experienced skin dryness when they felt skin sensitivity. In all, $55.9 \%$ (6129 out of 10,956) of the

Table 2 The Prevalence of Skin Sensitivity in Different Ages

\begin{tabular}{|l|l|l|l|l|}
\hline \multirow{2}{*}{ Age Range } & \multicolumn{2}{|l|}{ Non-Sensitive } & \multicolumn{2}{l|}{ Sensitive } \\
\cline { 2 - 5 } & $\mathbf{n}$ & $\%$ & $\mathbf{n}$ & $\%$ \\
\hline $18-20$ & 93 & $35.9 \%$ & 166 & $64.1 \%$ \\
$21-30$ & 942 & $34.2 \%$ & 1815 & $65.8 \%$ \\
$3 I-40$ & 1376 & $42.8 \%$ & 1837 & $57.2 \%$ \\
$4 I-50$ & 2627 & $49.2 \%$ & 2717 & $50.8 \%$ \\
$5 I-60$ & $306 I$ & $54.0 \%$ & 2604 & $46.0 \%$ \\
$6 I-70$ & 2394 & $60.7 \%$ & 1553 & $39.3 \%$ \\
$7 I-80$ & 636 & $70.7 \%$ & 264 & $29.3 \%$ \\
\hline Total & 11,129 & $50.4 \%$ & 10,956 & $49.6 \%$ \\
\hline
\end{tabular}

respondents declared sensitive skin but did not have these three symptoms. Only $0.3 \%$ of all three symptoms occurred simultaneously. The odds ratio of subjects with skin sensitivity reporting skin itchiness is 13.98 times greater than those of subjects without itchiness, while the odds ratio for skin redness is 4.94 times that of nonredness and that for dryness is 1.10 times that of nondryness. The relationships between sensitive skin and skin symptoms are shown in Figure 1.

\section{Prevalence According to Self-Declared Skin Type}

The sensitivity of skin was significantly associated with skin type, which was classified as neutral, dry, oily, or a combination type. The participants who declared that they had dry, oily, or combination skin more frequently $(P<0.001)$ reported having sensitive skin than those with neutral skin (Table 3). Participants with combination skin type were 1.63 times more likely to have sensitive skin than participants with neutral skin $(P<0.001)$.

\section{Prevalence According to Geographical Area}

Several provinces or municipalities with sample sizes greater than 500 in this study (Shanghai, Beijing, Guangdong, Henan, Sichuan, Chongqing, Shandong) showed significantly different prevalence of skin sensitivity $(P<0.001)$. Three municipalities have the highest prevalence of sensitivity: $59.0 \%$ of the participants were sensitive in Shanghai, $51.2 \%$ in Guangdong, and $49.6 \%$ in Beijing. The prevalence

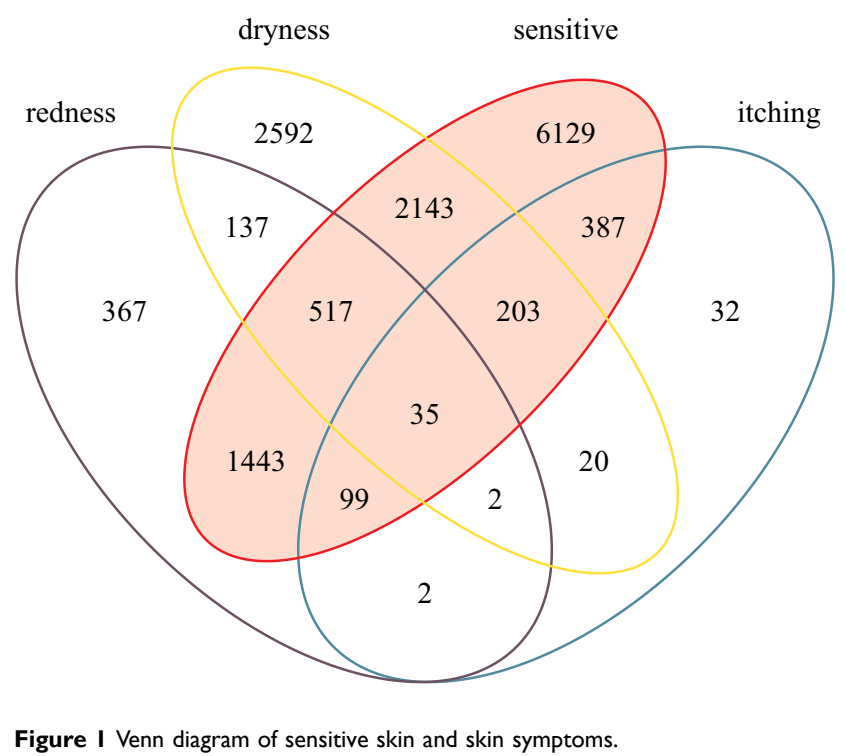


Table 3 Sensitive Skin Prevalence According to the Declaration of Skin Types

\begin{tabular}{|l|l|l|l|l|l|l|}
\hline Declaration of Skin Type & $\mathbf{n}$ & $\%$ & \multicolumn{2}{l|}{ Non-Sensitive } & \multicolumn{2}{l|}{ Sensitive } \\
\cline { 3 - 7 } & & & $\mathbf{n}$ & $\%$ & $\mathbf{n}$ \\
\hline Dry skin & 9110 & $41.2 \%$ & 4937 & $54.2 \%$ & 4173 & $45.8 \%$ \\
Neutral skin & 1260 & $5.7 \%$ & 741 & $58.8 \%$ & 519 & $41.2 \%$ \\
Combination skin & 10,617 & $48.1 \%$ & 4954 & $46.7 \%$ & 5663 & 510 \\
Oily skin & 957 & $4.3 \%$ & 447 & $46.7 \%$ & $93.3 \%$ \\
Not sure & 141 & $0.6 \%$ & 50 & $35.5 \%$ & $53.3 \%$ \\
\hline Total & 22,085 & $100.0 \%$ & 11,129 & $50.4 \%$ & 10,956 \\
\hline
\end{tabular}

of sensitivity in Henan, Shandong in northern China, and Chongqing, Sichuan in southwest China is lower, with the prevalence falling to $42.0 \%$ in Sichuan (Table 4).

\section{Effect of Cosmetic Product Usage}

We conducted a general logistic regression analysis of all possible risk factors for cosmetics usage related to sensitive skin, as shown in Table 5. In make-up usage, using three kinds of cosmetics products (out of exfoliant, facial masks, facial cleanser, or sunscreen), using cleansing oil or cream to remove make-up, or using three kinds of makeup remover (out of cleansing water, lotion, oil, cream, or wipes) are all risk factors to skin sensitivity (Figure 2).

\section{Effect of Lifestyle}

We also used a general logistic model to test the effect of skin sensitivity on different life habits. Mild stress or heavy stress, an annual average air quality index greater than 80 , sleep time less than 6 hours, and staying up late are all risk factors of sensitive skin.

Table 4 Sensitive Skin Prevalence According to the Geographical Areas

\begin{tabular}{|l|l|l|l|}
\hline \multirow{2}{*}{ Municipality or Province } & \multirow{2}{*}{ Total } & \multicolumn{2}{|l|}{ Sensitive } \\
\cline { 3 - 4 } & & $\mathbf{n}$ & $\%$ \\
\hline Shanghai & 1187 & 700 & $59.0 \%$ \\
Guangdong & 692 & 354 & $51.2 \%$ \\
Beijing & 2433 & 1207 & $49.6 \%$ \\
Henan & 2066 & 968 & $46.9 \%$ \\
Shandong & 2276 & 1054 & $46.3 \%$ \\
Chongqing & 1020 & 468 & $45.9 \%$ \\
Sichuan & 2678 & 1124 & $42.0 \%$ \\
Others & 6709 & 3376 & $50.3 \%$ \\
NA's & 3024 & 1705 & $56.4 \%$ \\
\hline Total & 22,085 & 10,956 & $49.6 \%$ \\
\hline
\end{tabular}

\section{Discussion}

\section{Sensitive Skin Prevalence in Different Regions}

We collected 22,085 questionnaires. Although this is not the first sensitivity survey conducted in China, this study covered various regions with a large sample size, providing informative data about skin sensitivity in Chinese women. The total prevalence of any degree of sensitivity in Chinese women in our surveyed population is $49.6 \%$; compared with a previous study in $2013,{ }^{18}$ this is an increase of $25.6 \%$ (49.6\% versus $39.5 \%)$. This change could be due to a greater concern for skin health in Chinese women or higher usage of skin cosmetic products. We also compared the prevalence of skin sensitivity in different countries (Table 6), and China has a medium sensitivity rate. These data agree on the ethnic difference of sensitivity, with Asians having a high prevalence compared with White people.

Moreover, we conducted separate statistical analyses of the questionnaire responses by region. Respondents from Beijing, Shanghai, and Guangdong had the highest incidence of sensitivity, followed by those in northern China (Henan and Shandong) and southwest China (Sichuan and Chongqing). The incidence of sensitivity in Sichuan was reduced to $42.0 \%$. It is likely that consumers in big cities are more exposed to advertisements about skincare products, and that they are more aware and concerned about skin sensitivity. In addition, more types of skincare products are used and there is heavy life stress. These factors might lead to a higher proportion of sensitive skin in large cities.

\section{Sensitive Skin Prevalence in Different Age and Skin Types}

In our data, it is found that a higher proportion of young adults have sensitive skin, and less than $40 \%$ of people 
Table 5 Sensitive Skin Prevalence According to the Usage of Cosmetic Product and Life Style

\begin{tabular}{|c|c|c|c|c|c|}
\hline Predictive Variables & Estimate & Standard Error & P-value & Odds Ratio & $95 \% \mathrm{Cl}$ \\
\hline Age & -0.03 & 0.00 & 0.001 & 0.973 & $0.97 I-0.975$ \\
\hline \multicolumn{6}{|l|}{ Skin type } \\
\hline Skin type dry vs neutral & 0.28 & 0.06 & 0.001 & 1.328 & $1.176-1.501$ \\
\hline Skin type combination vs neutral & 0.36 & 0.06 & 0.001 & 1.437 & $1.274-1.622$ \\
\hline Skin type oily vs neutral & 0.14 & 0.10 & 0.138 & 1.153 & $0.955-1.39 \mid$ \\
\hline \multicolumn{6}{|l|}{ Cosmetic product usage ${ }^{a}$} \\
\hline Apply 3 kinds cosmetic product vs less & 0.07 & 0.03 & 0.017 & 1.068 & $1.012-1.128$ \\
\hline \multicolumn{6}{|l|}{ Make-up frequency } \\
\hline Make-up everyday vs not & 0.01 & 0.05 & 0.857 & 1.008 & $0.923-1.101$ \\
\hline Make-up 2-3 times/week vs not & 0.16 & 0.07 & 0.028 & 1.177 & $1.018-1.36 \mid$ \\
\hline Occasionally make-up vs not & 0.11 & 0.03 & 0.002 & 1.111 & $1.040-1.188$ \\
\hline \multicolumn{6}{|l|}{ Types of make-up removers } \\
\hline Remover lotion/water vs facial cleanser & -0.07 & 0.06 & 0.297 & 0.937 & $0.829-1.059$ \\
\hline Remover oil/cream vs facial cleanser & 0.23 & 0.09 & 0.015 & 1.252 & $1.046-1.500$ \\
\hline Remover wipe vs facial cleanser & 0.15 & 0.12 & 0.216 & 1.164 & $0.915-1.482$ \\
\hline Apply 3 kinds removers vs less ${ }^{b}$ & 0.59 & 0.23 & 0.009 & 1.807 & $1.162-2.8105$ \\
\hline \multicolumn{6}{|l|}{ Life stress } \\
\hline Mild stress vs no stress & 0.27 & 0.03 & 0.001 & 1.305 & $1.225-1.390$ \\
\hline Heavy stress vs no stress & 0.45 & 0.06 & 0.001 & 1.574 & $1.402-1.766$ \\
\hline \multicolumn{6}{|l|}{ Time to sleep } \\
\hline Sleep at $22: 00-24: 00$ vs before $22: 00$ & 0.06 & 0.06 & 0.282 & 1.067 & $0.948-1.200$ \\
\hline Sleep at $24: 00-2: 00$ vs before $22: 00$ & 0.10 & 0.07 & 0.160 & 1.108 & $0.960-1.278$ \\
\hline Sleep late than $2: 00$ am vs before $22: 00 \mathrm{pm}$ & 0.59 & 0.22 & 0.007 & 1.812 & I.173-2.797 \\
\hline \multicolumn{6}{|l|}{ Sleep length } \\
\hline Sleep for 6 to 8 hours vs more 8 hours & 0.15 & 0.05 & 0.004 & 1.157 & $1.049-1.276$ \\
\hline Sleep less 6 hours vs more 8 hours & 0.30 & 0.07 & 0.001 & 1.357 & $1.194-1.54 \mid$ \\
\hline \multicolumn{6}{|l|}{ Air quality index } \\
\hline$A Q I>80$ vs $<80$ & 0.06 & 0.03 & 0.034 & 1.065 & $1.005-1.129$ \\
\hline
\end{tabular}

Notes: ${ }^{a}$ different kinds of cosmetic products used by subjects, including: exfoliant, facial mask, facial cleanser, sunscreen; ${ }^{b}$ different kinds of makeup remover used by subjects, including: makeup remover lotion/water, cleansing oil/cream, makeup remover wipe, facial cleanser.

over the age of 60 claim to have sensitive skin. In previous studies, it has also been found that the prevalence of sensitivity is closely related to age, but there are opposite findings. For example, Nilzén and Voss ${ }^{19}$ observed from patch test data that older people have higher reactivity to soaps and detergents, whereas Bettley and Donoghue ${ }^{20}$ reported a lower reactivity in older people. Coenraads ${ }^{21}$ demonstrated a higher skin reactivity to croton oil in older people, but no differences to thymoquinone or crotonaldehyde. In 1993, Grove ${ }^{22}$ reported a lower susceptibility of skin reactions in older subjects by testing croton oil, cationic and anionic surfactants, weak acids, and solvents. Robinson ${ }^{23}$ confirmed this lower reactivity, finding that skin reactivity is significantly less in a group of 56-74 years old than a younger age group. In terms of skin structure, as a person ages, the epidermis becomes thinner, the proportion of skin sebum also changes, and the possibility of sensitivity increases. ${ }^{24}$ However, the results of this study are the opposite, presumably because older participants have shifted their focus from sensitivity to aging problems, such as wrinkles and pigmentation. 




Figure 2 Logistic regression evaluating predictive factors for the skin sensitivity.

Skin sensitivity is associated with the type of skin, which is divided into dry, oily, combination, and neutral. The possible reason for the high rate of sensitive skin in combination skin types can be attributed to the imbalance of skin sebum excretion in certain facial areas; sebum is important in maintaining the barrier function. Thus, external stimuli induced skin sensitivity.

\section{Skin Symptoms Related to Sensitive Skin}

Some of the subjects with sensitive skin in this study also reported skin redness, itchiness, and dry skin symptoms. In all, 19\% of sensitive subjects experienced skin redness, predicting the onset of skin inflammation, or a past history of dermatitis. Also, 26\% reported skin dryness, which may

Table 6 Prevalence of Self-Declared Sensitive Skin in Various Geographies

\begin{tabular}{|l|l|l|l|}
\hline Countries & $\begin{array}{l}\text { Number of } \\
\text { Subjects }\end{array}$ & $\begin{array}{l}\text { Prevalence of } \\
\text { Sensitivity (\%) }\end{array}$ & Reference \\
\hline Korea & 1000 & $56.8 \%$ & {$[27]$} \\
Japan & 1500 & $54.5 \%$ & {$[12]$} \\
Italy & 500 & $53.8 \%$ & {$[13]$} \\
France & 1006 & $51.9 \%$ & {$[15]$} \\
China (women) & 22,085 & $49.6 \%$ & This study \\
USA & 994 & $44.6 \%$ & {$[14]$} \\
Russia & 1500 & $39.7 \%$ & {$[28]$} \\
Germany & 500 & $35.6 \%$ & {$[13]$} \\
Brazil & 1022 & $34.2 \%$ & {$[28]$} \\
Spain & 500 & $31.6 \%$ & {$[13]$} \\
\hline
\end{tabular}

enable irritants to be absorbed by the skin more easily. Notably, $7.18 \%$ of the subjects declared that they had itchiness but did not consider themselves as sensitive skin. While itchiness is a typical symptom of sensitivity, this may partially explain the low prevalence in this study compared with studies held in other countries. This result may indicate that some older subjects are not clear about the concept of sensitivity or the difference in skin manifestation.

\section{Factors Contributing to Skin Stress}

With the development of the cosmetics industry, more and more skincare products, types of make-up, and types of make-up remover have been produced. The number of people pursuing beauty has largely increased, and they use more skincare products containing active ingredients to achieve skin health. However, mixing a number of skincare products puts more stress on the skin. Repeated application of products of various textures and repeated cleansing might affect the integrity of the barrier structure, increasing epidermal water loss, and thereby affecting natural barrier function. At the same time, the usage of mixtures of various active ingredients might also be a potential irritant. These cause stress on modern human skin. ${ }^{25,26}$

Several life habits were identified as associated with aggravation of sensitivity of the skin, such as sleep duration, the time of going to sleep, and life stress. These factors can affect the level of inflammatory factors and contribute to skin sensitivity. 


\section{Conclusion}

We conducted a large-scale study of skin sensitivity in Chinese women. Being aged between 20 and 30, having a combination or oily skin type, living in the municipalities, being under life stress, or applying a number of cosmetic products will increase skin stress and contribute to skin sensitivity. This study provides data to support the improvement of sensitivity symptoms in the Chinese population. This large-scale, nationwide study provides informative data and elucidates critical factors of sensitive skin in Chinese women.

\section{Abbreviation}

ANOVA, analysis of variance.

\section{Disclosure}

Liyuan Qiao and Xiaoqing Xiao are co-first authors for this study. Fuguo Zuo and Rui Ye should be considered as joint corresponding authors for this study. The authors report no conflicts of interest in this work.

\section{References}

1. Frosch PJ, Kligman AM. A method for appraising the stinging capacity of topically applied substances. J Soc Cosmet Chem. 1977;28(5):197-209.

2. Farage MA, Katsarou A, Maibach HI. Sensory, clinical and physiological factors in sensitive skin: a review. Contact Dermatitis. 2006;55(1):1-14. doi:10.1111/j.0105-1873.2006.00886.x

3. Querleux B, Dauchot K, Jourdain R, et al. Neural basis of sensitive skin: an fMRI study. Skin Res Technol. 2008;14(4):454-461. doi:10.1111/j.1600-0846.2008.00312.x

4. Seidenari S, Francomano M, Mantovani L. Baseline biophysical parameters in subjects with sensitive skin. Contact Dermatitis. 1998;38(6):311-315. doi:10.1111/j.1600-0536.1998.tb05764.x

5. Misery L. Les nerfs à fleur de peau. [The nerves on edge]. Int $J$ Cosmet Sci. 2002;24(2):111-116. doi:10.1046/j.1467-2494.2002.00134.x

6. Reilly DM, Parslew R, Sharpe GR, Powell S, Green. MR. Inflammatory mediators in normal, sensitive and diseased skin types. Acta Derm Venereol. 2000;80(3):171-174.

7. Kumagai M, Nagano M, Suzuki H, Kawana S. Effects of stress memory by fear conditioning on nerve-mast cell circuit in skin. $J$ Dermatol. 2011;38(6):553-561. doi:10.1111/j.1346-8138.2010.01045.x

8. Ehnis-Pérez A, Torres-Álvarez B, Cortés-García D, HernándezBlanco D, Fuentes-Ahumada C, Castanedo-Cázares JP. Relationship between transient receptor potential vanilloid-1 expression and the intensity of sensitive skin symptoms. J Cosmet Dermatol. 2016;15 (3):231-237. doi:10.1111/jocd.12204

9. Kueper T, Krohn M, Haustedt LO, Hatt H, Schmaus G, Vielhaber G. Inhibition of TRPV1 for the treatment of sensitive skin. Exp Dermatol. 2010;19(11):980-986. doi:10.1111/j.1600-0625.2010.01122.x

10. Sun L, Wang X, Zhang Y, Wang T, Li X, Ma Y. The evaluation of neural and vascular hyper-reactivity for sensitive skin. Skin Res Technol. 2016;22(3):381-387. doi:10.1111/srt.12278
11. Misery L, Jourdan E, Abadie S, et al. Development and validation of a new tool to assess the Burden of Sensitive Skin (BoSS). J Eur Acad Dermatol Venereol. 2018;32(12):2217-2223. doi:10.1111/jdv.15186

12. Kamide R, Misery L, Perez-Cullell N, Sibaud V, Taieb C. Sensitive skin evaluation in the Japanese population. J Dermatol. 2013;40 (3):177-181. doi:10.1111/1346-8138.12027

13. Misery L, Boussetta S, Nocera T, Perez-Cullell N, Taieb C. Sensitive skin in Europe. J Eur Acad Dermatol Venereol. 2009;23(4):376-381. doi:10.1111/j.1468-3083.2008.03037.x

14. Misery L, Sibaud V, Merial-Kieny C, Taieb C. Sensitive skin in the American population: prevalence, clinical data, and role of the dermatologist. Int J Dermatol. 2011;50(8):961-967. doi:10.1111/ j.1365-4632.2011.04884.x

15. Misery L, Jourdan E, Huet F, et al. Sensitive skin in France: a study on prevalence, relationship with age and skin type and impact on quality of life. J Eur Acad Dermatol Venereol. 2018;32(5):791-795. doi:10.1111/jdv.14837

16. Farage MA, Mandl CP, Berardesca E, Maibach HI. Sensitive skin in China. J Cosmet Dermatol Sci Appl. 2012;2:184-195.

17. CMEE. Available from: https://www.mee.gov.cn/hjzl/dqhj/. Accessed July, 2020

18. Xu F, Yan S, Wu M, et al. Self-declared sensitive skin in China: a community-based study in three top metropolises. J Eur Acad Dermatol Venereol. 2013;27(3):370-375. doi:10.1111/j.14683083.2012.04648.x

19. Nilzén Å, Voss-Lagerlund K. Epicutaneous tests with detergents and a number of other common allergens. Dermatology. 1962;124 (1):42-52. doi:10.1159/000255056

20. Bettley FR, Donoghue E. The irritant effect of soap upon the normal skin. Br J Dermatol. 1960;72(2):67-76.

21. Coenraads PJ, Bleumink E, Nater JP. Susceptibility to primary irritants: age dependence and relation to contact allergic reactions. Contact Dermatitis. 1975;1(6):377-381. doi:10.1111/j.16000536.1975.tb05478.x

22. Grove GL. Age-Associated Changes in Integumental Reactivity. Clin Dermatol. 1993;4:227.

23. Robinson MK. Population differences in acute skin irritation responses: race, sex, age, sensitive skin and repeat subject comparisons. Contact Dermatitis. 2002;46(2):86-93. doi:10.1034/ j.1600-0536.2002.460205.x

24. Paquet F, Piérard-Franchimont C, Fumal I, Goffin V, Paye M, Piérard GE. Sensitive skin at menopause; dew point and electrometric properties of the stratum corneum. Maturitas. 1998;28(3):221-227. doi:10.1016/S0378-5122(97)00079-0

25. Jourdain R, Lacharrière O, De, Bastien P, Maibach HI. Ethnic variations in self-perceived sensitive skin: epidemiological survey. Contact Dermatitis. 2002;46(3):162-169. doi:10.1034/j.16000536.2002.460307.x

26. Pons-Guiraud A. Sensitive skin: a complex and multifactorial syndrome. J Cosmet Dermatol. 2004;3(3):145-148. doi:10.1111/ j.1473-2130.2004.00082.x

27. Kim YR, Cheon HI, Misery L, Taieb C, Lee YW. Sensitive skin in Korean population: an epidemiological approach. Skin Res Technol. 2018;24(2):229-234. doi:10.1111/srt.12418

28. Taieb C, Auges M, Georgescu V, Perez Cullell N, Misery L. Sensitive skin in Brazil and Russia: an epidemiological and comparative approach. Eur J Dermatol. 2014;24(3):372-376. doi:10.1684/ ejd.2014.2367 


\section{Publish your work in this journal}

Clinical, Cosmetic and Investigational Dermatology is an international, peer-reviewed, open access, online journal that focuses on the latest clinical and experimental research in all aspects of skin disease and cosmetic interventions. This journal is indexed on CAS.
The manuscript management system is completely online and includes a very quick and fair peer-review system, which is all easy to use. Visit http://www.dovepress.com/testimonials.php to read real quotes from published authors. 